\title{
Injury of the left brachiocephalic vein with hematoma and right sided pneumothorax after the insertion of a dialysis catheter
}

\author{
Marek Rębowski, Józef Kozak, Mariusz P. Łochowski \\ Department of Thoracic Surgery, Regional Multidisciplinary Center of Oncology and Traumatology, Lodz, Poland
}

Kardiochir Torakochir Pol 2019; 16 (3): 138-140

Central venous catheterization is one of the basic procedures performed in intensive care units. One of the indications for the introduction of the cannula is the need for renal replacement therapy. The procedure is associated with the risk of vessel perforation leading to life-threatening hemorrhage. In this type of complication the method of choice is surgical treatment of the damaged vessel.

We report the case of a 84-year-old woman, who was treated with hemodialysis due to advanced chronic kidney disease. On account of thrombosis in the femoral vein, the patient was qualified for introduction of a new catheter by puncturing the carotid junction of the internal carotid vein and subclavian vein using the Happaniemi and Slatis technique. In the intensive care unit under local anesthesia, a $15 \mathrm{~cm}$ long $12 \mathrm{~F}$ dialysis catheter was introduced. After this procedure hypotonia was observed. Computed tomography (CT) scan of the chest revealed the presence of the dialysis catheter tip in the right pleural cavity and right-sided pneumothorax with hematoma (Figures 1 and 2 A). The patient was transported to the Thoracic Surgery Department. A drain to the right pleural cavity was introduced on site. Due to the patient's stable condition and drainage from the pleural cavity, approx. $25 \mathrm{ml} / \mathrm{h}$, the patient was scheduled for surgery. The following day a partial longitudinal sternotomy was performed. Intraoperatively, injury of the left brachiocephalic vein by a dialysis catheter penetrating the right pleural cavity was detected (Figure 2 B). After withdrawal of the catheter, bleeding from the pierced vessel occurred, because the catheter itself partially blocked the bleeding by blocking the lesion site. The vessel was equipped with a continuous Premilene 3-0 suture. After treating injured vessels, under the control of sight the catheter was inserted into the superior vena cava. In order to ensure better hemostasis, a TachoSil hemostatic sponge (Figure $2 \mathrm{C}$ ) was used on the damaged venous vessel. No bleeding was observed. The Redon drain was left in the anterior mediastinum. The postoperative course was uneventful. The Redon drain was removed on the second postoperative day, and the drain from the pleural cavity on the $3^{\text {rd }}$ day. The patient was referred for dialysis treatment with an inserted catheter.

Bleeding after inserting the central venous catheter is a rare complication but potentially lethal. Its frequency according to various sources is estimated at $0.02-1.5 \%$. The hemorrhage may occur at many stages of the procedure. The selection of the catheter and the method of its introduction reduce the number of complications [1]. In our case the catheter used was too large and too stiff, so that it did not settle in the upper vena cava, pierced the vessel and entered the pleural cavity. Both during the procedure and after its completion, any deterioration of the patient's general condition should arouse suspicion of this complication [1]. Quickly undertaken diagnostics and treatment save the patient's life. The procedure of choice is the surgical treatment of a damaged vessel [2]. During the surgery, we decided that the removal of the catheter itself and treating the damaged vessel would not solve the need for urgent dialysis in the patient. Therefore, after sewing the pierced vein, the dialysis catheter under the control of sight was put in the correct place. For better hemostasis, a solid hemostatic agent may be considered. This method is commonly used for cardiac surgery and vascular surgery, which allows the bleeding from the previously surgically treated vessel to be reduced [3]. In our case, the hemostatic sponge effectively sealed the left brachiocephalic vein. It allowed us to quickly remove the drains from the mediastinum and the right pleural cavity ( 2 and 3 days postoperatively) and refer the patient to dialysis. Hemorrhage after catheterization of central veins is a rare complication requiring fast diagnostics. The choice of surgery method depends on the location of the lesion site and the dynamics of the bleeding.

\section{Disclosures}

The authors report no conflict of interest.

Address for correspondence: Mariusz P. Łochowski MD, Department of Thoracic Surgery, Regional Multidisciplinary Center of Oncology and Traumatology, Lodz, Poland, phone: +48 602776 887, e-mail: marilo@op.pl

Received: 2.07.2019, accepted: 15.08.2019. 

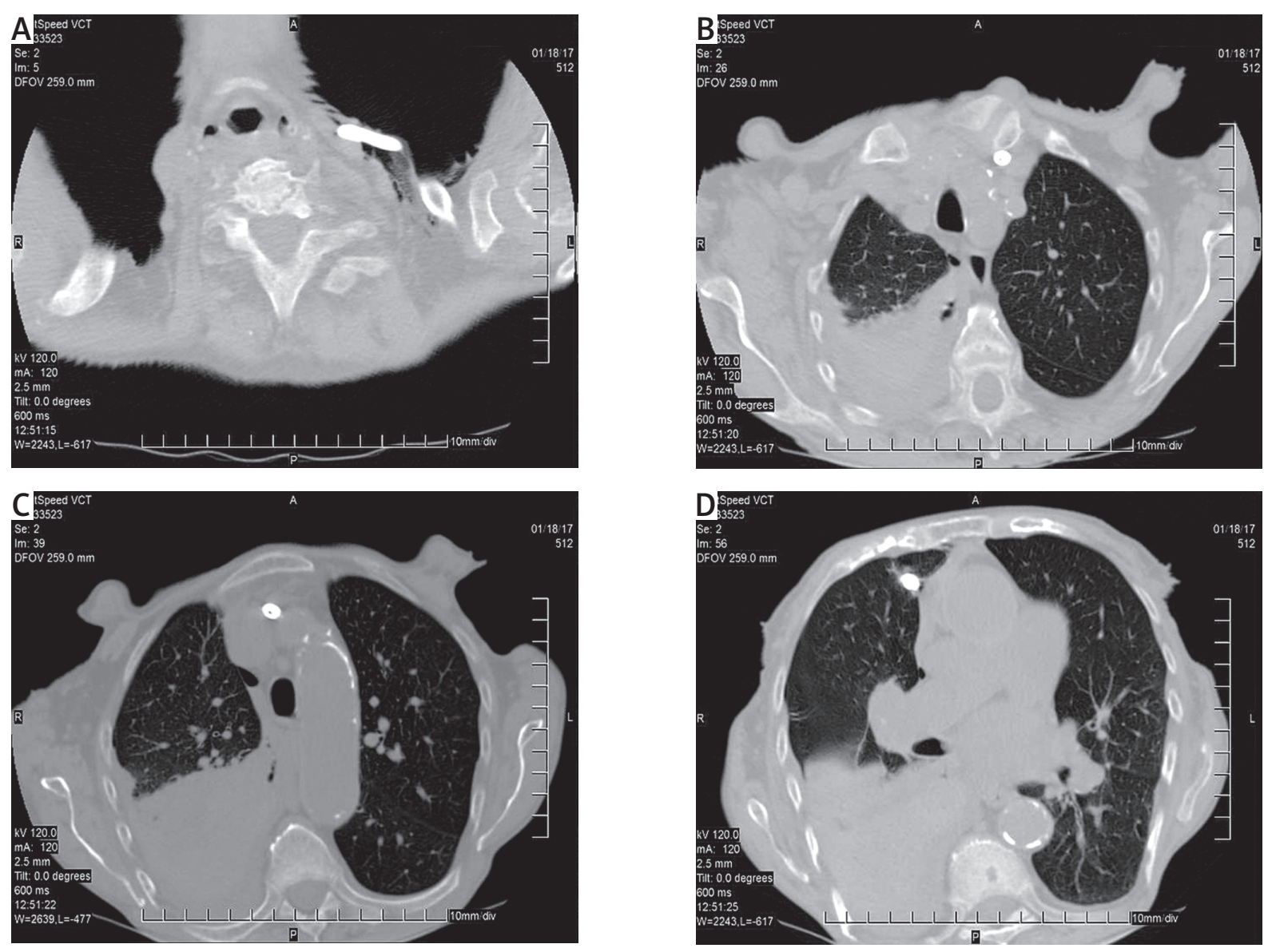

Figure 1. Computed tomography of the chest. Dialysis catheter tip in the right pleural cavity and right-sided pneumothorax with hematoma
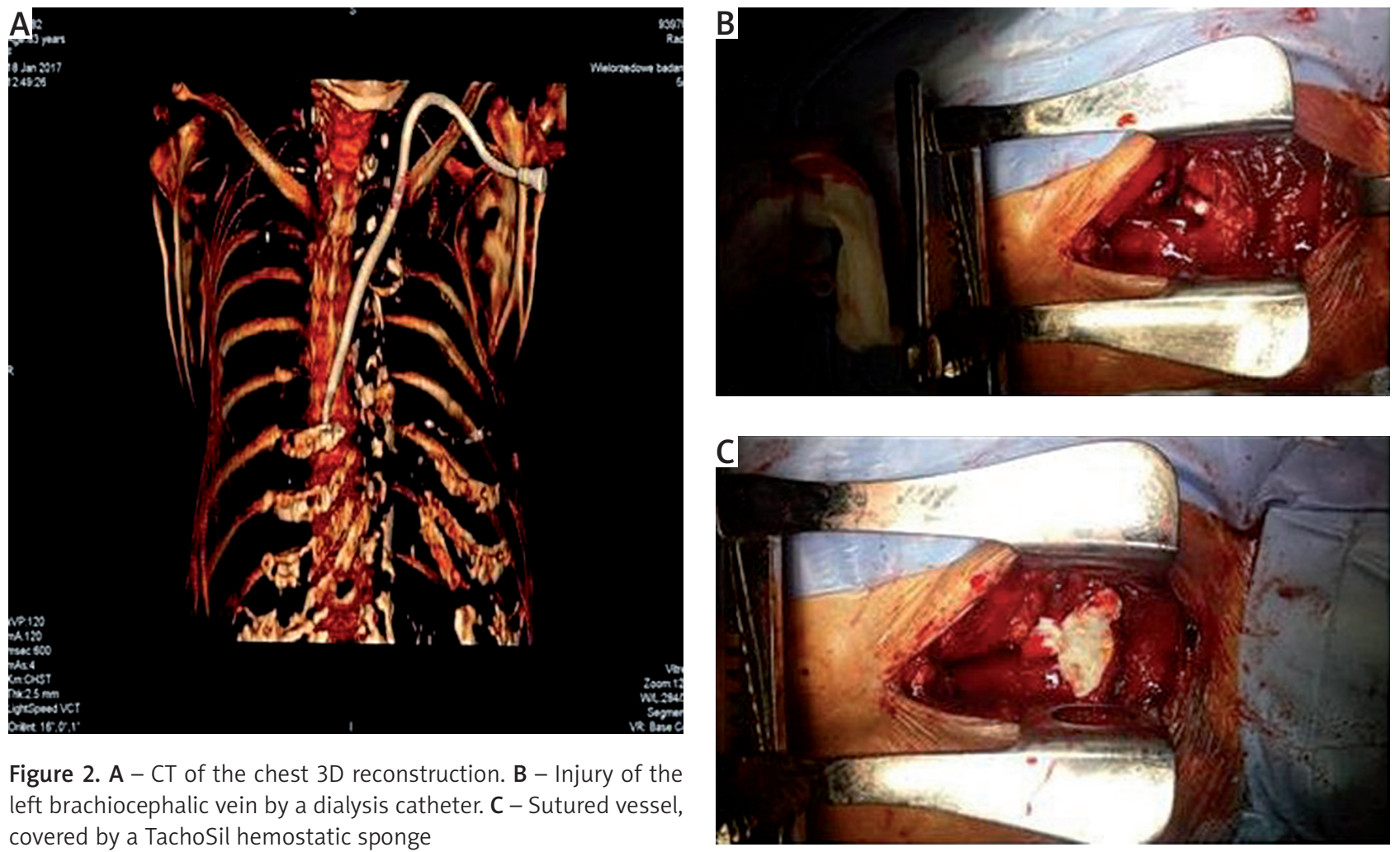

Figure 2. A - CT of the chest 3D reconstruction. B - Injury of the left brachiocephalic vein by a dialysis catheter. $\mathrm{C}$ - Sutured vessel, covered by a TachoSil hemostatic sponge 


\section{References}

1. Iwańczuk W, Guźniczak P, Kasperczak J. Krwawienie do jamy opłucnej jako powikłanie cewnikowana żyły podobojczykowej kaniulą dializacyjną - opis przypadku. Anesthesiol Intensive Ther 2013; 45: 93-96.

2. Wisheart JD, Hassan MA, Jackson JW. A complication of percutaneous cannulation of the internal jugular vein. Thorax 1972; 27: 496-499.
3. Dreqelid E, Ramnefiell MP, Erichsen C, Christensen BJ, Rawal R. Effective hemostasis in severe mesenteric vein laceration with tachosil( $\left({ }^{\circledR}\right)$, using a low or non-thrombogenic patch to prevent Tachosil((®)-induced thrombosis. Eur J Trauma Emerg Surg 2008; 34: 177-180. 